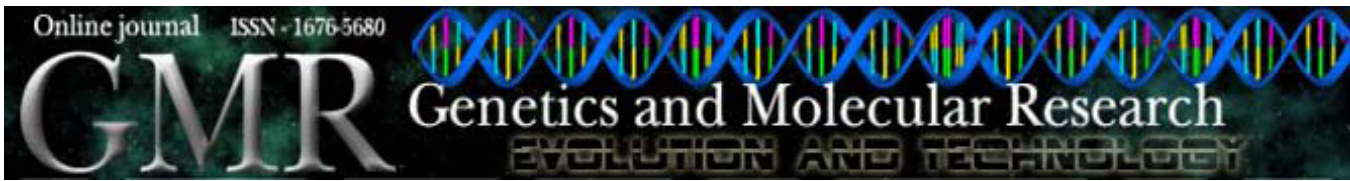

\title{
Investigation of NQO1 genetic polymorphism, NQO1 gene expression and PAH-DNA adducts in ESCC. A case-control study from Iran
}

\author{
H.A. Marjani ${ }^{1}$, F. Biramijamal ${ }^{1}$, N. Rakhshani ${ }^{2}$, A. Hossein-Nezhad ${ }^{1}$ \\ and R. Malekzadeh ${ }^{3}$ \\ ${ }^{1}$ National Institute of Genetic Engineering \& Biotechnology, Tehran, Iran \\ ${ }^{2}$ Gastrointestinal and Liver Diseases Research Center, \\ Iran University of Medical Sciences, Tehran, Iran \\ ${ }^{3}$ Digestive Diseases Research Center, Tehran University of Medical Sciences, \\ Tehran, Iran
}

Correspondence to: F. Biramijamal

E-mail: f.birami@nigeb.ac.ir

Genet. Mol. Res. 9 (1): 239-249 (2010)

Received October 19, 2009

Accepted December 21, 2009

Published February 9, 2010

\begin{abstract}
We evaluated the effect of NQO1 genetic variation on PAH-DNA adducts in esophageal squamous cell carcinoma (ESCC) in northeast Iran. Golestan Province in northeast of Iran has one of the highest esophageal cancer incidences in the world. The study included 93 ESCC cases and 50 control individuals who were seen at the clinical cancer center in Golestan province. NQO1 C609T genotypes were determined by PCR-RFLP analysis. NQO1 gene expression in tissue samples was determined by quantitative real-time PCR. Immunohistochemical techniques were used to detect PAH-DNA adducts in ESCC and normal esophageal tissues. The distributions of NQO1 genetic polymorphism between cases and the control group were not significantly different. NQO1 gene expression was not higher in tumor tissues than in normal esophageal tissues adjacent to the ESCC; expression was higher in tumor tissues that had the NQO1 T allele. NQO1 gene expression was high in normal esophageal tissues. The level of PAH-DNA adducts was significantly higher in ESCC tissues of cases than in normal tissues adjacent to tumor tissues and in normal esophageal tissues of healthy con-
\end{abstract}


trols. There were no significant differences between the adduct levels of normal esophageal tissues of patients and controls. There was also no significant relationship between cigarette smoking and PAH-DNA adducts. We concluded that PAHs are a risk factor for ESCC and that PAH-DNA adducts have potential as a biomarker for risk of ESCC.

Key words: NQO1; Esophageal squamous cell carcinoma (ESCC); Northeast Iran; PAH-DNA adduct

\section{INTRODUCTION}

The sixth most common cause of cancer mortality worldwide is esophageal cancer (Parkin et al., 2001). Golestan Province in Northeast Iran is among the highest esophageal cancer incidence areas in the world and the age-standardized rate for this cancer is over 100 in 100,000 for both genders (Mahboubi et al., 1973). The geographical differences of esophageal squamous cell carcinoma (ESCC) incidences depend on environmental and genetic factors (D’Errico et al., 1999).

Polycyclic aromatic hydrocarbons (PAHs) consist of several linked benzene structures, which are generated during incomplete combustion and pyrolysis of organic substances (Poirier, 2004). A remarkable number of human cancers are known to be related to exposure to PAHs, like other chemical carcinogens (Bartsch, 2000; Hecht, 2003; Poirier, 2004), which can induce mutations in human cells (Mahboubi et al., 1973; Bartsch, 2000; Poirier, 2004). PAHs are also produced during high-temperature cooking, cigarette smoking and organic fuel burning (Elovaara et al., 2007). The vast environmental distribution of PAHs results in a great deal of human exposure to them. Also because of their lipophilic nature, PAHs are easily absorbed and distributed in the whole human body (Franco et al., 2008). PAHs are metabolized by xenobiotic metabolizing enzymes, which convert xenobiotic compounds into more hydrophilic and polar metabolites for their easier excretion in human body fluids. Urine samples from individuals who live in Northeast Iran have been shown to contain high levels of 1-hydroxypyrene glucuronide (1-OHPG). This compound is the urine metabolite of benzo[ $\alpha]$ pyrene (Kamangar et al., 2005; Fagundes et al., 2006). Also, high levels of PAHs were observed in mate beverage in high prevalent areas for ESCC in Brazil; mate herb leaves are dried by hot wood smoke or burning gas or oil, so that these dried leaves become highly rich in PAH compounds (Kamangar et al., 2008). Additionally, it has been shown that residents of Golestan Province have high levels of 1-OHPG as a PAH biomarker in urine samples. These results were reported by the Digestive Diseases Research Center of Tehran University of Medical Sciences, where this finding did not differ by gender, age or habitation whether rural or urban, and interestingly, there were no differences regarding cigarette smoking habits (Kamangar et al., 2005).

One of the most important of these enzymes is $\mathrm{NADP}(\mathrm{H})$ :quinone oxidoreductase 1 (NQO1) (Shimada, 2006). However, in the process of these metabolic reactions, some unstable PAH metabolites are highly reactive and may attack the DNA molecule, which results in the formation of PAH-DNA adducts (Poirier, 2004; Shimada, 2006).

$\mathrm{NAD}(\mathrm{P}) \mathrm{H}$ :quinone oxidoreductase, which was first called DT-diaphorase, has the ability to detoxify a large number of environmental and synthetic carcinogens (Zhang et al., 2003b; Sarbia et al., 2003). A polymorphism of C to T in the 609th codon of NQO1 
DNA leads to the formation of the NQO1*2 allele, which is markedly weak in its biochemical activity. The NQO1 $\mathrm{T}$ allele has only $2-4 \%$ enzymatic activity in comparison to its wild-type form. Cells homozygous for the polymorphic NQO1 allele (T/T) express NQO1 mRNA, but they have no detectable NQO1 protein because the mutant NQO1 protein is rapidly degraded by the proteasomal system (Siegel et al., 2001). This C to $\mathrm{T}$ substitution causes a proline to serine change in the 187th amino acid location of the NQO1 protein sequence. A relationship between NQO1 T allele and upper gastrointestinal malignancies has been shown (Zhang et al., 2003a). The heterozygous phenotype for the T allele for NQO1 gene has 3-fold weaker enzyme activity, and that homozygous for T allele has almost complete enzyme activity loss (Zhang et al., 2003b). NQO1 gene expression is stimulated by oxidative compounds such as PAHs and also antioxidants (Long et al., 2001). Additionally, it is elevated in some human cancers such as breast, colon, and lung, and normally in the human body, stomach and trachea have the highest levels of NQO1 expression (Sharp et al., 2000; Kolesar et al., 2002; Cleton-Jansen et al., 2008).

We conducted a study to evaluate the effect of NQO1 genetic variation on PAH-DNA adducts in ESCC from Northeast Iran because no PAH-DNA adduct and NQO1 genetic variation data are available in the literature on tumors from this region. We analyzed NQO1 genetic variation in 93 patients and 50 healthy individuals and PAH-DNA adducts in 29 ESCC; 29 normal adjacent tumor tissues and 27 normal esophageal tissues from healthy individuals (the tissues from paraffin blocks were available). Additional tumor and normal tissues from frozen samples were available for 11 patients and 5 healthy individuals, allowing the NQO1 gene expression assessment (by quantitative real-time polymerase chain reaction, PCR). The data for the NQO1 gene expression in tumor and normal tissues were compared with the result of NQO1 variation and PAH-DNA adducts.

\section{MATERIAL AND METHODS}

We examined 93 cases including 52 males and 41 females with a mean age of $65.04 \pm$ 11.21 years, who were the patients with ESCC where their malignancy was confirmed by endoscopy (clinically) and pathology (tissue diagnosis) (Table 1). The area of study was Northeast Iran, Golestan Province, where almost 50\% of inhabitants are Turkmen. The cases were referred by local physicians to Atrak Clinic in Khatam Hospital at Gonbad City, which is a special center for gastroesophageal cancers. ESCC cases for the study were enrolled between the years 2002 and 2008. The criteria for enrollment were an age of at least 18 years and be resident of the study area at registration time, with no concurrent or previous history of other cancer in any organ. Also, 50 controls with no malignancy and/or severe diseases, including 22 males and 28 females, with a mean age of $61.26 \pm 10.36$ years (Table 1) were enrolled from Atrak Clinic in Khatam Hospital at Gonbade Kavous City in Golestan Province, between the years 2002 and 2008, with the same age and residence criteria as for the cases. These controls came to the clinic for regular gastrointestinal check-ups or consultations for some non-serious gastrointestinal problem.

According to Table 1, the mean age was $61.26 \pm 10.36$ years for the control group and $65.04 \pm 11.21$ for the case group, $\mathrm{P}=0.049$. Of the total sample population (143), $93(65 \%)$ were cases and $50(35 \%)$ were controls. With regard to gender distribution, $28(56 \%)$ of controls were females and $22(44 \%)$ were males and in the case group, $41(44.1 \%)$ were females and $52(55.9 \%)$ were males $(\mathrm{P}=0.17)$. The cases and controls were referred to the Atrak Clinic 
in Khatam Hospital at Gonbad City of Golestan Province in Northeast Iran between the years 2002 and 2008, and their minimum age for enrollment was 18 years. Demographic characteristics of cases and controls are categorized in Table 1.

Genomic DNA of cases and controls was obtained from whole blood samples by the QIAGEN Flexigen kit for blood samples. The extracted DNA was then kept in a $-20^{\circ} \mathrm{C}$ freezer until further use.

NQO1 polymorphism genotyping by PCR was performed in a $25-\mu \mathrm{L}$ reaction volume containing $100 \mathrm{ng}$ genomic DNA and $0.5 \mathrm{~mL} 10 \mathrm{pM}$ forward and reverse primers, $2.5 \mu \mathrm{L} 10 \mathrm{X}$ PCR buffer, $1.25 \mathrm{U}$ Taq DNA polymerase, $0.8 \mu \mathrm{L} 10 \mathrm{mM} \mathrm{MgCl}_{2}$, and $0.5 \mu \mathrm{L} 0.1 \mathrm{mM}$ of each dNTP. The primers were F: 5'-AAGCCCAGACCAACTTCT-3' and R: 5'-ATTTGAATTC GGGCGTCTGCTG-3'. The thermocycling program consisted of an initial denaturation for 14 min at $94^{\circ} \mathrm{C}$ followed by 40 cycles at $94^{\circ} \mathrm{C}$ for $1 \mathrm{~min}$ for denaturation, $56^{\circ} \mathrm{C}$ for $1 \mathrm{~min}$ for annealing and $72^{\circ} \mathrm{C}$ for $2 \mathrm{~min}$ for extension. The PCR product was a 172-bp amplicon. The PCR product was digested by $20 \mathrm{U} \operatorname{Hinfl}$ enzyme (Fermentas) for $3 \mathrm{~h}$ at $37^{\circ} \mathrm{C}$, and the digestion product was then run on a 3\% agarose gel. The normal NQO1 allele (C) is not cut by the Hinf1 enzyme at the polymorphic site, but the polymorphic $\mathrm{T}$ allele is cut into 131- and 41-bp bands. Thus, the homozygous wild-type $(\mathrm{C} / \mathrm{C})$ individuals have one band, homozygous polymorphic $(\mathrm{T} / \mathrm{T})$ individuals have two bands, and the heterozygote $(\mathrm{C} / \mathrm{T})$ individuals have three bands.

Of the 93 ESCCs examined in this study for the NQO1 genetic polymorphism, frozen samples of 11 ESCC cases (11 of tumor and 11 of normal adjacent to the tumor tissues) and 5 normal tissues from healthy controls were available for evaluation of mRNA expression for NQO1 gene. Esophageal tumor and normal tissues were taken from ESCC patients and healthy controls by endoscopic biopsy, and then, the samples immersed in RNA solution (QIAGEN) for RNA preservation, where the tissue-containing tubes were kept in a $-70^{\circ} \mathrm{C}$ freezer for later use. RNA extraction was performed by the QIAGEN RNeasy Kit, and the RNA samples were kept at $-70^{\circ} \mathrm{C}$.

For analysis of NQO1 gene expression we used the real-time PCR method with the Roche Lightcycler apparatus. Real-time PCR were carried out in a $25-\mu \mathrm{L}$ reaction volume in Roche capillaries. The reaction mixture contains $0.5 \mu \mathrm{L}$ TaKaRa Ex.taq and $12.5 \mu \mathrm{L}$ TaKaRa one-step Master mix, and $0.5 \mu \mathrm{L}$ TaKaRa RT primers, $7.5 \mu \mathrm{L}$ TaKaRa RNase-free DI water, forward and reverse NQO1 RT primers, each one $10 \mathrm{pmoL}$, and $2 \mu \mathrm{L}$ tissue total RNA containing $250 \mathrm{ng}$ total tissue mRNA. For internal control, we used $\beta$-actin for normalizing the expression values between all samples and obtaining comparative expression values relative to $\beta$-actin.

Primers for the reactions were NQO1: forward: 5'-AAGCAGTGCTTTCCATCA-3' and reverse: 5'-TCCTGCCTGGAAGTTTAG-3', which give a 283-bp amplicon, and for $\beta$ actin: forward: 5'-GAGACCTTCAACACCCCAGCC-3' and reverse: 5'-AGACGCAGGAT GGCATGGG-3', which give a 140-bp amplicon.

For each of the real-time amplifications, we prepared a standard curve by running real-time PCR with five 10-fold diluted cDNAs as template for NQO1 and $\beta$-actin, separately.

Therefore, in each run for samples we had reactions for NQO1 and $\beta$-actin for every sample and one standard sample for NQO1, one standard sample for $\beta$-actin, and also a negative control for NQO1 and a negative control for $\beta$-actin. NQO1 to $\beta$-actin comparative values were obtained as final expression values for each of the tumor tissues and the normal tissues, both for cases and healthy controls. NQO1:real-time program consisted of three phases; a reverse transcription phase for $5 \mathrm{~min}$ at $42^{\circ} \mathrm{C}$, then an amplification-quantification phase of 50 
cycles of one denaturation step at $95^{\circ} \mathrm{C}$ for $5 \mathrm{~s}$ and one elongation step at $60^{\circ} \mathrm{C}$ for $35 \mathrm{~s}$, and a final phase of melting by increasing the temperature from $65^{\circ}$ to $100^{\circ} \mathrm{C}$ in $15 \mathrm{~s}$.

Of the 93 ESCCs examined in this study for the NQO1 genetic polymorphism, paraffin blocks of 29 ESCC cases (tumor and normal adjacent to tumor tissues) and 27 normal tissues from healthy controls were available for PAH-DNA adduct analysis. Esophageal tumor and normal tissues were taken from ESCC patients and healthy controls by upper GI endoscopy performed by expert GI specialists. The samples were stored in $10 \%$ formalin and then prepared to make paraffin-embedded blocks. Tissue sections $(3 \mu \mathrm{m})$ were applied to precoated glass slides, and after dewaxing were subjected to microwave antigen retrieval in citrate buffer. To block nonspecific reactivity and staining from endogenous peroxidase, sections were incubated in hydrogen peroxide $(0.3 \%)$ for $30 \mathrm{~min}$ and normal goat serum $(10 \%)$ for $30 \mathrm{~min}$. After rinsing, slides were incubated overnight at $4^{\circ} \mathrm{C}$ with primary anti-BPDE-DNA antibody; 8e11 (HM5008, HBT-Cell Sciences, dilution 1:100). After washing with PBS, the secondary antibody (Invision ${ }^{\mathrm{TM}}$ mouse) was added to the slides. Finally, DAB kit was applied to the samples with an incubation of 10 $\mathrm{min}$. The control-positive and control-negative samples were kindly prepared by our colleagues at the International Agency for Research on Cancer, Lyon, France. The percentage of positive PAH-DNA adduct-stained nuclei was the basis for our scoring of the samples for PAH-DNA adduct levels; the score 0 was given for no staining samples, score 1 for $1-10 \%$ positive-stained nuclei, score 2 for $11-50 \%$ stain, and score 3 for $51 \%$ or more positive-stained nuclei (Lai et al., 2006). The results of the immunohistochemistry (IHC) scores were compared between cases and controls. In this study, ESCC tissues and normal esophageal tissues of 29 cases (tumor and normal adjacent tumor tissues) and normal esophageal tissues of 28 controls were analyzed by IHC, and also, the results of IHC were compared to the individuals' cigarette smoking habits.

\section{Statistical analysis}

For comparison of NQO1 gene expression means, we used the Student $t$-test, and ANOVA was applied for comparison of multiple groups in regard to their quantitative expression levels. For genotype distribution analysis, the chi-square test for qualitative variables was performed. The chi-square test was also used for Hardy-Weinberg analysis of the observed and expected genotype frequencies. The statistical method applied for comparing PAH-DNA adduct levels between the tissues was the Fisher exact test. A 5\% probability level was taken as statistically significant in this study, and the odds ratio (OD) was calculated with 95\% confidence interval (CI). All statistical analyses were performed using the SPSS software (version 15).

\section{RESULTS}

According to Table 1, mean age was $61.26 \pm 10.36$ years for the control group and $65.04 \pm 11.21$ for the case group, $\mathrm{P}=0.049$. Of the total sample population (143), $93(65 \%)$ were cases and $50(35 \%)$ were controls. For gender distribution, $28(56 \%)$ of controls were females and $22(44 \%)$ were males, and in the case group, $41(44.1 \%)$ were females and 52 $(55.9 \%)$ were males $(\mathrm{P}=0.17)$. The cases and controls were referred to Atrak Clinic, Khatam Hospital in Gonbad City of Golestan Province in Northeast Iran between the years 2002 and 2008, and their minimum age for enrollment was 18 years. Demographic characteristics of cases and controls are shown in Table 1. 
Table 1. Age and gender distribution of cases and controls of the study.

\begin{tabular}{lccc}
\hline & Cases $(\mathrm{N}=93)$ & Controls $(\mathrm{N}=50)$ & $\mathrm{P}$ \\
\hline Age (years, mean $\pm \mathrm{SD})$ & $65.04 \pm 11.21$ & $61.26 \pm 10.36$ & 0.049 \\
Female $(\mathrm{N}, \%)$ & $41(44.1 \%)$ & $28(56 \%)$ & 0.17 \\
Male $(\mathrm{N}, \%)$ & $52(55.9 \%)$ & $22(44 \%)$ & 0.17 \\
\hline
\end{tabular}

The NQO1 T/T genotype frequency was compared between cases and the control group, and this difference was not significant $\left(P=0.448, \chi^{2}=1.605\right.$; Table 2$)$. The observed values of genotype percentages was 0.9999 for the case group and 1.00 for the control group, which correlated with Hardy-Weinberg equilibrium $(\mathrm{P} \geq 0.05)$.

\begin{tabular}{|c|c|c|c|c|}
\hline & \multicolumn{4}{|c|}{ NQO1 C609 polymorphism } \\
\hline & $\mathrm{C} / \mathrm{C}$ & $\mathrm{C} / \mathrm{T}$ & $\mathrm{T} / \mathrm{T}$ & $\mathrm{T}$ allele frequency \\
\hline Cases & $51(54.8 \%)$ & $35(37.6 \%)$ & $7(7.5 \%)$ & $49(26.3 \%)$ \\
\hline Controls & $22(44 \%)$ & $24(48 \%)$ & $4(8 \%)$ & $32(32 \%)$ \\
\hline Total & $73(51.04 \%)$ & $59(41.25 \%)$ & $11(7.89 \%)$ & $81(28.32 \%)$ \\
\hline
\end{tabular}

$\left(\chi^{2}=1.605, \mathrm{P}=0.448\right)$. Data are reported as number with percent in parentheses.

NQO1 gene expression was analyzed for normal tissues adjacent to the tumors of cases $(0.00329 \pm 0.00095)$ and controls $(0.00272 \pm 0.00132)$, and there was no significant difference between the two groups $(\mathrm{P}=0.234)$. Tumor tissue expression of NQO1 was compared to that of normal tissues, and this analysis showed no significant variation between the two groups $(\mathrm{P}=$ 0.128). This finding was also analyzed with a non-parametric method, and the result was similar to that for the parametric one $(\mathrm{P}=0.286)$. NQO1 gene expression was analyzed for its relationship with the NQO1 C609T genotype; in normal tissues there was no relationship of the genotype with gene expression $(\mathrm{P}=0.39)$. In tumor tissues, however, there was an almost significant relationship with NQO1 genotype and NQO1 gene expression $(\mathrm{P}=0.062$; Table 3$)$. In our investigation, we found that ESCC samples with T allele (TT or CT genotypes) had higher NQO1 gene expression than the samples with $\mathrm{CC}$ genotype $(\mathrm{P}=0.01)$. This value shows a significant linearity and a meaningful trend from $\mathrm{C} / \mathrm{C}$ to $\mathrm{C} / \mathrm{T}$ and $\mathrm{T} / \mathrm{T}$ genotypes and increasing $\mathrm{NQO} 1$ gene expression.

\begin{tabular}{lccc}
\multicolumn{2}{c}{ Table 3. Means of NQO1 gene expression and genotypes for tissues of cases and controls. } \\
\hline \multirow{2}{*}{ NQO1 C609T genotype } & \multicolumn{2}{c}{ Case } & Control \\
\cline { 2 - 4 } & Tumor & Normal (adjacent to tumor) & Normal \\
\hline C/C & 0.0022 & 0.0034 & 0.0039 \\
& $(\mathrm{~N}=4)$ & $(\mathrm{N}=4)$ & $(\mathrm{N}=2)$ \\
$\mathrm{C} / \mathrm{T}$ & 0.0067 & 0.0034 & 0.0021 \\
& $(\mathrm{~N}=6)$ & $(\mathrm{N}=6)$ & $(\mathrm{N}=2)$ \\
$\mathrm{T} / \mathrm{T}$ & 0.011 & 0.0018 & 0.0016 \\
& $(\mathrm{~N}=1)$ & $(\mathrm{N}=1)$ & $(\mathrm{N}=1)$ \\
Mean & 0.0066 & 0.0028 & 0.0025 \\
\hline
\end{tabular}


All adduct scorings of the samples with their numbers are shown in Table 4. The majority of positive samples were in the 1 scoring category.

Table 4. The number of samples with their scores of adduct levels for tumor tissues, normal esophageal tissue
adjacent to tumors and normal esophageal tissues of healthy controls.
\begin{tabular}{lcccc}
\hline Tissue & Score 0 & Score $1+$ & Score $2+$ & Score $3+$ \\
\hline Tumor PAH-DNA adducts (29 cases) & 15 & 13 & 0 & 1 \\
Case normal esophageal tissue PAH-DNA adducts (29 cases) & 27 & 0 & 0 & 2 \\
Control esophageal tissue PAH-DNA adducts (27 controls) & 26 & 0 & 1 & 0
\end{tabular}

Tumor adducts were significantly compared to normal tissues of cases $(\mathrm{P}=0.0008)$. The odds ratio was 12.6 with 95\% CI of 2.31-63.8. The difference between ESCC tissues and normal esophageal tissues of the healthy controls was statistically significant $(\mathrm{P}=0.0002)$. Odds ratio $=24.26 ; 95 \% \mathrm{CI}=2.89-203.48$.

PAH-DNA adducts in ESCC tissues were compared to the normal esophageal tissues in the same cases. Tumor adducts were significantly higher compared to normal tissues of cases $(\mathrm{P}=0.0008)$, where the $\mathrm{OD}=12.6$ and $95 \% \mathrm{CI}=2.31-63.8$.

Adduct levels in ESCC tissues were statistically significant $(\mathrm{P}=0.0002)$ compared with the normal esophageal tissues of healthy controls, with an $\mathrm{OD}=24.26$ and $95 \% \mathrm{CI}=2.89-203.48$.

The normal esophageal tissue adducts of cases were compared to those of healthy controls, but there was no significant difference in adduct levels between the two groups $(\mathrm{P}=0.9)$. In regard to the levels of adducts in cigarette smokers, in the case group the PAH-DNA adducts of tumor nuclei showed no significant difference between smokers and non-smokers $(\mathrm{P}=0.5)$. In normal esophageal tissues, adduct levels showed no significant difference between smokers and non-smokers $(\mathrm{P}=0.3)$.

Because the polymorphisms of the genes of four xenobiotic-metabolizing enzymes (NQO1, CYP2C9, GSTT1, and GSTM1) of cases and controls had been analyzed before and were available, these polymorphisms were evaluated for any relationship between them and the adduct levels. We examined whether PAH-DNA adduct levels are higher in polymorphic allele-containing genotypes or not.

In our study population, there were three genotypes for the $\mathrm{NQO} 1 * 2$ allele: wild-type homozygote $(\mathrm{C} / \mathrm{C})$, heterozygote $(\mathrm{C} / \mathrm{T})$ and polymorphic homozygote $(\mathrm{T} / \mathrm{T})$ genotypes. We compared PAH-DNA adduct levels in ESCC tissues and esophageal normal tissues in the three $\mathrm{NQO} 1 * 2$ allele genotypes, and no significant differences were seen in the tumor tissue analysis $(\mathrm{P}=0.9)$ and in the normal esophageal tissue analysis $(\mathrm{P}=0.3)$ in the adduct levels between the three genotypes $(\mathrm{C} / \mathrm{C}, \mathrm{C} / \mathrm{T}, \mathrm{T} / \mathrm{T})$.

In the evaluation of NQO1 enzyme polymorphism with occurrence of PAH-DNA adduct, we did not find any relationship between the polymorphic genotypes and adduct levels, and thus, maybe some other enzymes are involved in the elimination of xenobiotics preventing adduct formation. Also, we did not find a significant difference by comparing PAH-DNA adduct levels in healthy control normal esophagus tissues versus normal esophageal tissues adjacent to ESCC of the patients.

\section{DISCUSSION}

In regard to NQO1 gene polymorphisms, a study performed by Zhang et al. (2003b) on the relationship of the NQO1 T allele with the risk for ESCC and gastric cardiac adenocarcinoma in north 
China, showed that the $\mathrm{T} / \mathrm{T}$ genotype was significantly more prevalent in case groups than in controls, and it was suggested that this genotype may represent a higher risk of ESCC and gastric cardiac adenocarcinoma. However, in the present study, we did not see a significant difference between case and control groups in their T/T genotype frequencies. Even the $\mathrm{C} / \mathrm{T}$ genotype was more frequent in the control group than in the case group, but this difference was also not of statistical value. Thus, it seems that having the NQO1 T allele is not a predisposing genetic risk factor in Northeast Iran.

In another study in China and Germany, the T/T genotype has been shown to pose a significant risk for developing ESCC (Zhang et al., 2003a).

To understand the effect of the genetic polymorphisms investigated on susceptibility to esophageal cancer, we suggest future studies with patients in other cities with different risks of ESCC to compare with our results.

In this study, we noticed that NQO1 relative to $\beta$-actin gene expression is not higher in ESCC than in normal esophageal tissues; these findings are not in agreement with the studies performed on breast, colon and lung carcinomas. In a classification of esophageal tissue expression results in relation to their underlying NQO1*2 allele (C609T) genotypes, we found that in esophageal tumor tissues NQO1 gene expression is elevated as the T allele emerges in the genotype. That is, we found more expression in $\mathrm{C} / \mathrm{T}$ genotypes than in $\mathrm{C} / \mathrm{C}$ genotypes and even more expression in the $\mathrm{T} / \mathrm{T}$ genotype compared to $\mathrm{C} / \mathrm{T}$ genotypes. In $\mathrm{C} / \mathrm{C}$ genotype tumors, $\mathrm{NQO}$ gene expression was not significantly higher than in normal esophageal tissues adjacent to the tumors. In normal esophageal tissues, we did not see an association between the presence of NQO1 T allele and NQO1 gene expression. Zhang et al. (2003a) reported a gradual decrease in NQO1 protein expression in $\mathrm{C} / \mathrm{T}$ to $\mathrm{T} / \mathrm{T}$ genotypes in comparison to $\mathrm{C} / \mathrm{C}$ genotypes of ESCC using an IHC method. Sarbia et al. (2003) reported such pattern of NQO1 protein expression in esophageal adenocarcinoma by IHC, but no relationship of NQO1 genotypes with NQO1 mRNA expression was found. In the present study, NQO1 gene expression was analyzed at the mRNA level, and the results may differ from what was found in the studies that determined expression at the protein level.

In the majority of human body tissues, the expression of NQO1 is at minimal levels. This low level of expression is kept under negative control by Nrf3 transcription factor, whereas the other close relative to it, the Nrf2 transcription factor, has a positive effect on NQO1 gene expression. Both transcription factors attach to the ARE element on the NQO1 promoter and control the expression process of the gene downstream (Sankaranarayanan and Jaiswal, 2004). NQO1 gene expression increases in response to oxidant and electrophilic radicals to counteract oxidative and electrophilic stresses, and in fact, this is a kind of chemopreventive defense mechanism for cells (Sankaranarayanan and Jaiswal, 2004).

It seems that the high gene expression of NQO1 in tumor cells is due to increased cellular metabolism in malignancy, as we know that tumor cells are at a really augmented level of proliferation and metabolism, which gives rise to many oxidative radicals and stressing cellular wastes, thus triggering the synthesis of a battery of chemoprotective enzymes such as NQO1 and GSTs, HO1, and $\gamma$-GCS against stressors such as reactive oxygen species (Sankaranarayanan and Jaiswal, 2004). The impaired levels of NQO1 protein may induce the cell to express more NQO1 mRNA. It was shown that NQO1 stabilizes p53 protein and helps the integrity of cell cycle (Sankaranarayanan and Jaiswal, 2004).

In the presence of NQO1 T allele, the protein's life span becomes too short, and the NQO1 level in the cell is near zero. This lack of the protein stimulates the cell to keep the NQO1 transcription at an elevated level to compensate for the lack of the protein, which seems 
to be more exaggerated in the case of the T/T genotype. Besides, these cells try to save their p53 proteins by the aid of their NQO1 protein, but there is no present and active NQO1, so again, the NQO1 promoter remains at an active level.

In this study, we did not find tumor tissues with NQO1 expression higher than that of normal tissues, but when we compared the expression between three genotypes of tumor esophageal tissues, $\mathrm{C} / \mathrm{C}$ and $\mathrm{C} / \mathrm{T}$ and $\mathrm{T} / \mathrm{T}$, we found a progressive increase in NQO1 expression. As the tissue becomes malignant, its genotype may affect its NQO1 expression.

The elevated NQO1 expression in tissues that have low expression in their normal states may be a valuable diagnostic key for alteration in the normal cell cycle and its deviation toward a carcinogenesis process.

Further studies are needed to reveal how NQO1 gene expression in tissues differs based on their biological state, normal or tumor, and their genotype, and if this expression changes in metaplasias representing an alarm for on-going malignant changes.

Archival paraffin-embedded tissue blocks are shown to be suitable sources for evaluation of PAH-DNA adducts as a good biomarker of exposure (van Gijssel et al., 2004). Cigarette smoke is a rich source of many PAHs (Bartsch, 2000; Akpan et al., 2006), so the relation of cigarette smoking and PAH-DNA adduct levels was also investigated in this study.

We supposed that PAH-DNA adducts are a risk factor for ESCC, because they are easily distributed throughout the human body (Wang et al., 2008). PAHs can be converted by cellular enzymes to DNA-reactive products, which have the capability to attach to DNA molecules and to be inserted in place of nucleotides. Especially if a combination of genotypes of polymorphic nucleotide excision repair genes exists in a person, the presence of PAH-DNA adducts may be a risk for breast cancer (Crew et al., 2007). Our data showed that the number of PAH-DNA adducts is remarkably high in ESCC tissues compared to normal esophageal tissues of the same cases and esophageal tissues of healthy controls. When we compared the normal esophageal tissues of the cases and controls, there was no significant difference between the two groups, a finding that suggests that the presence of PAH-DNA adducts is a phenomenon that is related to ESCC carcinogenesis.

Nonetheless, our study cases and controls are both from one geographical region, and the adduct levels are high in the cases. In a study on ESCC in China (van Gijssel et al., 2002), the adduct levels were higher in cases than in controls but the habitation area of cases was a high ESCC prevalent area in China and the controls were from the United States.

Another study on colon cancer has mentioned the relationship between PAH-DNA adducts and colon cancer risk (Al-Saleh et al., 2008).

Some studies based on immunological techniques have examined the relationship between breast cancer and PAH-DNA adducts (Santella et al., 2000; Tang et al., 2003; Crew et al., 2007; Sagiv et al., 2009; McCarty et al., 2009). There were no strong statistical values confirming the relationship between cigarette smoking and increased risk of PAH in breast cancer (Santella et al., 2000). We could not find any significant effect of cigarette smoking on PAH-DNA adduct levels and ESCC risk.

Contrary to our findings on ESCC, some studies on the role of PAHs in prostatic cancer do not strongly support the role of PAHs in prostatic cancer risk (Rybicki et al., 2004; John et al., 2009).

According to the Digestive Diseases Research Center of Tehran University of Medical Sciences, the measure of high levels of 1-OHPG in northeastern areas of Iran suggests an 
extensive and high exposure to PAHs in the region's inhabitants, and this finding did not differ by gender and age and habitation whether rural or urban; interestingly, there were no differences regarding cigarette smoking habits (Kamangar et al., 2005).

The smoking habits of cases and controls showed no relationship between cigarette smoking and levels of PAH-DNA adducts.

In conclusion, our findings demonstrate the role of PAHs as a risk factor of ESCC and the potential of PAH-DNA adducts for being a biomarker of risk for ESCC. Although we could not find any significant relationship between cigarette smoking and the adducts, we suggest that this subject be investigated with greater sample sizes and more quantitative methods for human and environmental samples.

\section{ACKNOWLEDGMENTS}

Research supported by Tehran University of Medical Sciences and National Institute of Genetic Engineering and Biotechnology, Project \#291. There was no conflict of interest. We thank Dr. Dariush Nasrollahzadeh, Dr. Ramin Shakeri, Dr. Karim Aghcheli, Dr. Farhad Eslami, Ms. Safora Kor, Mr. Ashor Yolmeh, Mrs. Azimi, Ms. Mohammadian, and Dr. Ahmad Nosrati for their valuable participation in the collection of material.

\section{REFERENCES}

Akpan V, Huang S, Lodovici M and Dolara P (2006). High levels of carcinogenic polycyclic aromatic hydrocarbons (PAH) in 20 brands of Chinese cigarettes. J. Appl. Toxicol. 26: 480-483.

Al-Saleh I, Arif J, El-Doush I, Al-Sanea N, et al. (2008). Carcinogen DNA adducts and the risk of colon cancer: casecontrol study. Biomarkers 13: 201-216.

Bartsch H (2000). Studies on biomarkers in cancer etiology and prevention: a summary and challenge of 20 years of interdisciplinary research. Mutat. Res. 462: 255-279.

Cleton-Jansen AM, van Eijk R, Lombaerts M, Schmidt MK, et al. (2008). ATBF1 and NQO1 as candidate targets for allelic loss at chromosome arm 16q in breast cancer: absence of somatic ATBF1 mutations and no role for the C609T NQO1 polymorphism. BMC Cancer 8: 105.

Crew KD, Gammon MD, Terry MB, Zhang FF, et al. (2007). Polymorphisms in nucleotide excision repair genes, polycyclic aromatic hydrocarbon-DNA adducts, and breast cancer risk. Cancer Epidemiol. Biomarkers Prev. 16: 2033-2041.

D'Errico A, Malats N, Vineis P and Boffetta P (1999). Review of studies of selected metabolic polymorphisms and cancer. IARC Sci. Publ. 148: 323-393.

Elovaara E, Mikkola J, Stockmann-Juvala H, Luukkanen L, et al. (2007). Polycyclic aromatic hydrocarbon (PAH) metabolizing enzyme activities in human lung, and their inducibility by exposure to naphthalene, phenanthrene, pyrene, chrysene, and benzo(a)pyrene as shown in the rat lung and liver. Arch. Toxicol. 81: 169-182.

Fagundes RB, Abnet CC, Strickland PT, Kamangar F, et al. (2006). Higher urine 1-hydroxy pyrene glucuronide (1-OHPG) is associated with tobacco smoke exposure and drinking mate in healthy subjects from Rio Grande do Sul, Brazil. BMC Cancer 6: 139.

Franco SS, Nardocci AC and Gunther WM (2008). PAH biomarkers for human health risk assessment: a review of the state-of-the-art. Cad. Saude Publica 24 (Suppl 4): s569-s580.

Hecht SS (2003). Tobacco carcinogens, their biomarkers and tobacco-induced cancer. Nat. Rev. Cancer 3: 733-744.

John K, Ragavan N, Pratt MM, Singh PB, et al. (2009). Quantification of phase I/II metabolizing enzyme gene expression and polycyclic aromatic hydrocarbon-DNA adduct levels in human prostate. Prostate 69: 505-519.

Kamangar F, Strickland PT, Pourshams A, Malekzadeh R, et al. (2005). High exposure to polycyclic aromatic hydrocarbons may contribute to high risk of esophageal cancer in northeastern Iran. Anticancer Res. 25: 425-428.

Kamangar F, Schantz MM, Abnet CC, Fagundes RB, et al. (2008). High levels of carcinogenic polycyclic aromatic hydrocarbons in mate drinks. Cancer Epidemiol. Biomarkers Prev. 17: 1262-1268.

Kolesar JM, Pritchard SC, Kerr KM, Kim K, et al. (2002). Evaluation of NQO1 gene expression and variant allele in 
human NSCLC tumors and matched normal lung tissue. Int. J. Oncol. 21: 1119-1124.

Lai TJ, Tsai YY, Cheng YW, Chiang CC, et al. (2006). An association between BPDE-like DNA adduct levels and P53 gene mutation in pterygium. Mol. Vis. 12: 1687-1691.

Long DJ, Waikel RL, Wang XJ, Roop DR, et al. (2001). NAD(P)H:quinone oxidoreductase 1 deficiency and increased susceptibility to 7,12-dimethylbenz[a]-anthracene-induced carcinogenesis in mouse skin. J. Natl. Cancer Inst. 93: 1166-1170.

Mahboubi E, Kmet J, Cook PJ, Day NE, et al. (1973). Oesophageal cancer studies in the Caspian Littoral of Iran: the Caspian cancer registry. Br. J. Cancer 28: 197-214.

McCarty KM, Santella RM, Steck SE, Cleveland RJ, et al. (2009). PAH-DNA adducts, cigarette smoking, GST polymorphisms, and breast cancer risk. Environ. Health Perspect. 117: 552-558.

Parkin DM, Bray F, Ferlay J and Pisani P (2001). Estimating the world cancer burden: Globocan 2000. Int. J. Cancer 94: 153-156.

Poirier MC (2004). Chemical-induced DNA damage and human cancer risk. Nat. Rev. Cancer 4: 630-637.

Rybicki BA, Rundle A, Savera AT, Sankey SS, et al. (2004). Polycyclic aromatic hydrocarbon-DNA adducts in prostate cancer. Cancer Res. 64: 8854-8859.

Sagiv SK, Gaudet MM, Eng SM, Abrahamson PE, et al. (2009). Polycyclic aromatic hydrocarbon-DNA adducts and survival among women with breast cancer. Environ. Res. 109: 287-291.

Sankaranarayanan K and Jaiswal AK (2004). Nrf3 negatively regulates antioxidant-response element-mediated expression and antioxidant induction of NAD(P)H:quinone oxidoreductase1 gene. J. Biol. Chem. 279: 50810-50817.

Santella RM, Gammon MD, Zhang YJ, Motykiewicz G, et al. (2000). Immunohistochemical analysis of polycyclic aromatic hydrocarbon-DNA adducts in breast tumor tissue. Cancer Lett. 154: 143-149.

Sarbia M, Bitzer M, Siegel D, Ross D, et al. (2003). Association between NAD(P)H:quinone oxidoreductase 1 (NQO1) inactivating C609T polymorphism and adenocarcinoma of the upper gastrointestinal tract. Int. J. Cancer 107: 381-386.

Sharp SY, Kelland LR, Valenti MR, Brunton LA, et al. (2000). Establishment of an isogenic human colon tumor model for NQO1 gene expression: application to investigate the role of DT-diaphorase in bioreductive drug activation in vitro and in vivo. Mol. Pharmacol. 58: 1146-1155.

Shimada T (2006). Xenobiotic-metabolizing enzymes involved in activation and detoxification of carcinogenic polycyclic aromatic hydrocarbons. Drug Metab. Pharmacokinet. 21: 257-276.

Siegel D, Anwar A, Winski SL, Kepa JK, et al. (2001). Rapid polyubiquitination and proteasomal degradation of a mutant form of NAD(P)H:quinone oxidoreductase 1. Mol. Pharmacol. 59: 263-268.

Tang D, Rundle A, Mooney L, Cho S, et al. (2003). Sulfotransferase 1A1 (SULT1A1) polymorphism, PAH-DNA adduct levels in breast tissue and breast cancer risk in a case-control study. Breast Cancer Res. Treat. 78: 217-222.

van Gijssel HE, Divi RL, Olivero OA, Roth MJ, et al. (2002). Semiquantitation of polycyclic aromatic hydrocarbonDNA adducts in human esophagus by immunohistochemistry and the automated cellular imaging system. Cancer Epidemiol. Biomarkers Prev. 11: 1622-1629.

van Gijssel HE, Schild LJ, Watt DL, Roth MJ, et al. (2004). Polycyclic aromatic hydrocarbon-DNA adducts determined by semiquantitative immunohistochemistry in human esophageal biopsies taken in 1985. Mutat. Res. 547: 55-62.

Wang S, Chanock S, Tang D, Li Z, et al. (2008). Assessment of interactions between PAH exposure and genetic polymorphisms on PAH-DNA adducts in African American, Dominican, and Caucasian mothers and newborns. Cancer Epidemiol. Biomarkers Prev. 17: 405-413.

Zhang J, Schulz WA, Li Y, Wang R, et al. (2003a). Association of NAD(P)H: quinone oxidoreductase 1 (NQO1) C609T polymorphism with esophageal squamous cell carcinoma in a German Caucasian and a northern Chinese population. Carcinogenesis 24: 905-909.

Zhang JH, Li Y, Wang R, Geddert H, et al. (2003b). NQO1 C609T polymorphism associated with esophageal cancer and gastric cardiac carcinoma in North China. World J. Gastroenterol. 9: 1390-1393. 